\title{
Research Article \\ Strong Convergence of Non-Implicit Iteration Process with Errors in Banach Spaces
}

\author{
Yan Hao, Xiaoshuang Wang, and Aihua Tong \\ School of Mathematics, Physics, and Information Science, Zhejiang Ocean University, \\ Zhoushan 316004, China \\ Correspondence should be addressed to Yan Hao, zjhaoyan@yahoo.cn
}

Received 1 September 2012; Accepted 17 October 2012

Academic Editor: Xiaolong Qin

Copyright (C) 2012 Yan Hao et al. This is an open access article distributed under the Creative Commons Attribution License, which permits unrestricted use, distribution, and reproduction in any medium, provided the original work is properly cited.

The purpose of this paper is to study the strong convergence of a non-implicit iteration process with errors for asymptotically I-nonexpansive mappings in the intermediate sense in the framework of Banach spaces. The results presented in this paper extend and improve the corresponding results recently announced.

\section{Introduction and Preliminaries}

Let $K$ be a nonempty, closed, and convex subset of a real Banach space $X$ and let $T: K \rightarrow K$ be a mapping. In this paper, we use $F(T)$ to stand for the set of fixed points of $T$, that is $F(T)=\{x \in K: T x=x\}$.

Recall that $T$ is said to be nonexpansive if

$$
\|T x-T y\| \leq\|x-y\|, \quad \forall x, y \in K .
$$

$T$ is said to be asymptotically nonexpansive if there exists a sequence $\left\{h_{n}\right\}$ with $h_{n} \subset$ $[1,+\infty)$ with $\lim _{n \rightarrow \infty} h_{n}=1$ such that

$$
\left\|T^{n} x-T^{n} y\right\| \leq h_{n}\|x-y\|, \quad \forall x, y \in K, n \geq 1 .
$$


$T$ is said to be asymptotically nonexpansive in the intermediate sense if it is continuous and the following inequality holds:

$$
\limsup _{n \rightarrow \infty} \sup _{x, y \in k}\left(\left\|T^{n} x-T^{n} y\right\|-\|x-y\|\right) \leq 0
$$

Observe that if we define $a_{n}=\sup _{x, y \in k}\left(\left\|T^{n} x-T^{n} y\right\|-\|x-y\|\right), \sigma_{n}=\max \left\{0, a_{n}\right\}$, then $\sigma_{n} \rightarrow 0$ as $n \rightarrow \infty$ and (1.3) reduces to

$$
\left\|T^{n} x-T^{n} y\right\| \leq\|x-y\|+\sigma_{n}, \quad \forall x, y \in K, n \geq 1
$$

It is easy to see that every nonexpansive mapping is asymptotically nonexpansive. And every asymptotically nonexpansive mapping is asymptotically nonexpansive in the intermediated sense. In [1], Goebel and Kirk proved that, if $K$ is a nonempty closed convex bounded subset of a real uniformly convex Banach space $X$, and $T$ is an asymptotically nonexpansive self-mapping on $K$, then $T$ has a fixed point in $K$. The class of mappings which are asymptotically nonexpansive in the intermediat sense was investigated by Bruck et al. [2] and Kirk [3]. Since then, many authors have investigated the fixed point problem of these mappings based on implicit iterative methods or non-implicit iterative methods; see, for example, [4-21].

Let $I: K \rightarrow K$ be a mapping. Recall that $T$ is said to be asymptotically $I$-nonexpansive if there exists a sequence $\left\{h_{n}\right\}$ with $\left\{h_{n}\right\} \subset[1,+\infty)$ with $\lim _{n \rightarrow \infty} h_{n}=1$ such that

$$
\left\|T^{n} x-T^{n} y\right\| \leq h_{n}\left\|I^{n} x-I^{n} y\right\|, \quad \forall x, y \in K, n \geq 1 .
$$

Recently, weak and strong convergence theorems for fixed points of $I$-nonexpansive mappings, and asymptotically I-nonexpansive mappings have been established by many scholar, see, for example, [22-25].

In this paper, we consider a new mapping based on asymptotically nonexpansive mappings in the intermediate sense and asymptotically $I$-nonexpansive mappings.

Let $T: K \rightarrow K, I: K \rightarrow K$ be two mappings. $T$ is said to be asymptotically $I$ nonexpansive in the intermediate sense if it is continuous and the following inequality holds:

$$
\limsup _{n \rightarrow \infty} \sup _{x, y \in k}\left(\left\|T^{n} x-T^{n} y\right\|-\left\|I^{n} x-I^{n} y\right\|\right) \leq 0
$$

Observe that if we define $a_{n}=\sup _{x, y \in k}\left(\left\|T^{n} x-T^{n} y\right\|-\left\|I^{n} x-I^{n} y\right\|\right), \sigma_{n}=\max \left\{0, a_{n}\right\}$, then $\sigma_{n} \rightarrow 0$ as $n \rightarrow \infty$ and (1.6) reduces to

$$
\left\|T^{n} x-T^{n} y\right\| \leq\left\|I^{n} x-I^{n} y\right\|+\sigma_{n}, \quad \forall x, y \in K, n \geq 1 .
$$

Note that if $I=\mathrm{Id}$, where Id is the identity mapping, then (1.7) reduces to (1.4).

In this paper, we investigate asymptotically $I$-nonexpansive mappings in the intermediate sense based on a non-implicit iterative algorithm. Strong convergence of the implicit iterative algorithm is obtained in the framework of Banach spaces.

In order to prove our main results, we need the following lemmas. 
Lemma 1.1 (see [21]). let $X$ be a uniformly convex Banach space. Let $b$ and $c$ be two constants with $0<b<c<1$. Suppose that $\left\{t_{n}\right\}$ is a sequence in $[b, c]$. Let $\left\{x_{n}\right\}$ and $\left\{y_{n}\right\}$ be two sequences in $X$ such that

$$
\begin{gathered}
\limsup _{n \rightarrow \infty}\left\|x_{n}\right\| \leq d, \quad \limsup _{n \rightarrow \infty}\left\|y_{n}\right\| \leq d, \\
\lim _{n \rightarrow \infty}\left\|t_{n} x_{n}+\left(1-t_{n}\right) y_{n}\right\|=d
\end{gathered}
$$

hold for some $d \geq 0$, then $\lim _{n \rightarrow \infty}\left\|x_{n}-y_{n}\right\|=0$.

Lemma 1.2 (see [26]). Let $\left\{a_{n}\right\},\left\{b_{n}\right\}$, and $\left\{c_{n}\right\}$ be three nonnegative sequences satisfying the following condition:

$$
a_{n+1} \leq\left(1+b_{n}\right) a_{n}+c_{n}, \quad \forall n \geq n_{0}
$$

where $n_{0}$ is some nonnegative integer, $\sum_{n=1}^{\infty} b_{n}<\infty$ and $\sum_{n=1}^{\infty} c_{n}<\infty$. Then the limit $\lim _{n \rightarrow \infty} a_{n}$ exists.

\section{Main Results}

Lemma 2.1. Let $X$ be a real Banach space and $K$ a nonempty closed and convex subset of $X$. Let $T: K \rightarrow K$ be a asymptotically I-nonexpansive in the intermediate sense and $I: K \rightarrow K a$ asymptotically nonexpansive in the intermediate sense. Assume that $F:=F(T) \cap F(I) \neq \emptyset$. Let $\sigma_{n}=$ $\max \left\{0, \sup _{x, y \in k}\left(\left\|T^{n} x-T^{n} y\right\|-\left\|I^{n} x-I^{n} y\right\|\right)\right\}$ and $\bar{\sigma}_{n}=\max \left\{0, \sup _{x, y \in k}\left(\left\|T^{n} x-T^{n} y\right\|-\|x-y\|\right)\right\}$. Let $\left\{\alpha_{n}\right\},\left\{\beta_{n}\right\},\left\{\gamma_{n}\right\},\left\{\widehat{\alpha}_{n}\right\},\left\{\widehat{\beta}_{n}\right\},\left\{\widehat{\gamma}_{n}\right\}$ be six real number sequences in $(0,1)$. Let $\left\{x_{n}\right\}$ be a sequence generated in the following iterative process:

$$
\begin{gathered}
x_{1} \in C, \\
y_{n}=\widehat{\alpha}_{n} x_{n}+\widehat{\beta}_{n} I^{n} x_{n}+\widehat{\gamma}_{n} v_{n}, \\
x_{n+1}=\alpha_{n} x_{n}+\beta_{n} T^{n} y_{n}+\gamma_{n} u_{n}, \quad n \geq 1,
\end{gathered}
$$

where $\left\{u_{n}\right\}$ and $\left\{v_{n}\right\}$ be two bounded sequences in $K$. Assume that the following restrictions are satisfied:
(a) $\alpha_{n}+\beta_{n}+\gamma_{n}=\widehat{\alpha}_{n}+\widehat{\beta}_{n}+\widehat{\gamma}_{n}=1$;
(b) $\sum_{n=1}^{\infty} \sigma_{n}<\infty, \sum_{n=1}^{\infty} \bar{\sigma}_{n}<\infty$;
(c) $\sum_{n=1}^{\infty} \gamma_{n}<\infty, \sum_{n=1}^{\infty} \widehat{\gamma}_{n}<\infty$.

Then $\lim _{n \rightarrow \infty}\left\|x_{n}-p\right\|$ exists for all $p \in F$. 
Proof. Letting $p \in F$, we see that

$$
\begin{aligned}
\left\|y_{n}-p\right\| & =\left\|\left(1-\widehat{\beta}_{n}-\widehat{\gamma}_{n}\right) x_{n}+\widehat{\beta}_{n} I^{n} x_{n}+\widehat{\gamma}_{n} v_{n}-p\right\| \\
& \leq\left(1-\widehat{\beta}_{n}-\widehat{\gamma}_{n}\right)\left\|x_{n}-p\right\|+\widehat{\beta}_{n}\left\|I^{n} x_{n}-p\right\|+\widehat{\gamma}_{n}\left\|v_{n}-p\right\| \\
& \leq\left(1-\widehat{\beta}_{n}-\widehat{\gamma}_{n}\right)\left\|x_{n}-p\right\|+\widehat{\beta}_{n}\left(\left\|x_{n}-p\right\|+\bar{\sigma}_{n}\right)+\widehat{\gamma}_{n}\left\|v_{n}-p\right\| \\
& =\left(1-\widehat{\gamma}_{n}\right)\left\|x_{n}-p\right\|+\widehat{\gamma}_{n}\left\|v_{n}-p\right\|+\widehat{\beta}_{n} \bar{\sigma}_{n} \\
& \leq\left\|x_{n}-p\right\|+\widehat{\gamma}_{n}\left\|v_{n}-p\right\|+\widehat{\beta}_{n} \bar{\sigma}_{n} \\
\left\|x_{n+1}-p\right\| & =\left\|\left(1-\beta_{n}-\gamma_{n}\right) x_{n}+\beta_{n} T^{n} y_{n}+\gamma_{n} u_{n}-p\right\| \\
& \leq\left(1-\beta_{n}-\gamma_{n}\right)\left\|x_{n}-p\right\|+\beta_{n}\left\|T^{n} y_{n}-p\right\|+\gamma_{n}\left\|u_{n}-p\right\| \\
& =\left(1-\beta_{n}-\gamma_{n}\right)\left\|x_{n}-p\right\|+\beta_{n}\left\|T^{n} y_{n}-T^{n} p\right\|+\gamma_{n}\left\|u_{n}-p\right\| \\
& \leq\left(1-\beta_{n}-\gamma_{n}\right)\left\|x_{n}-p\right\|+\beta_{n}\left(\left\|I^{n} y_{n}-I^{n} p\right\|+\sigma_{n}\right)+\gamma_{n}\left\|u_{n}-p\right\| \\
& =\left(1-\beta_{n}-\gamma_{n}\right)\left\|x_{n}-p\right\|+\beta_{n}\left\|I^{n} y_{n}-I^{n} p\right\|+\beta_{n} \sigma_{n}+\gamma_{n}\left\|u_{n}-p\right\| \\
& \leq\left(1-\beta_{n}-\gamma_{n}\right)\left\|x_{n}-p\right\|+\beta_{n}\left(\left\|y_{n}-p\right\|+\bar{\sigma}_{n}\right)+\beta_{n} \sigma_{n}+\gamma_{n}\left\|u_{n}-p\right\| \\
& =\left(1-\beta_{n}-\gamma_{n}\right)\left\|x_{n}-p\right\|+\beta_{n}\left\|y_{n}-p\right\|+\gamma_{n}\left\|u_{n}-p\right\|+\beta_{n}\left(\sigma_{n}+\bar{\sigma}_{n}\right) \\
& \leq\left(1-\beta_{n}\right)\left\|x_{n}-p\right\|+\beta_{n}\left\|y_{n}-p\right\|+\gamma_{n}\left\|u_{n}-p\right\|+\beta_{n}\left(\sigma_{n}+\bar{\sigma}_{n}\right) .
\end{aligned}
$$

Substituting (2.2) into (2.3),we obtain that

$$
\begin{aligned}
\left\|x_{n+1}-p\right\| \leq & \left(1-\beta_{n}\right)\left\|x_{n}-p\right\|+\beta_{n}\left(\left\|x_{n}-p\right\|+\widehat{\gamma}_{n}\left\|v_{n}-p\right\|+\widehat{\beta}_{n} \bar{\sigma}_{n}\right) \\
& +\gamma_{n}\left\|u_{n}-p\right\|+\beta_{n}\left(\sigma_{n}+\bar{\sigma}_{n}\right) \\
= & \left\|x_{n}-p\right\|+\left[\beta_{n} \widehat{\gamma}_{n}\left\|v_{n}-p\right\|+\gamma_{n}\left\|u_{n}-p\right\|+\beta_{n} \sigma_{n}+\beta_{n} \bar{\sigma}_{n}\left(1+\widehat{\beta}_{n}\right)\right] .
\end{aligned}
$$

Let $a_{n}=\left\|x_{n}-p\right\|, b_{n}=0$, and

$$
c_{n}=\beta_{n} \widehat{\gamma}_{n}\left\|v_{n}-p\right\|+\gamma_{n}\left\|u_{n}-p\right\|+\beta_{n} \sigma_{n}+\beta_{n} \bar{\sigma}_{n}\left(1+\widehat{\beta}_{n}\right) .
$$

It follows from (2.4) that

$$
a_{n+1} \leq a_{n}+c_{n}
$$

In view of the restrictions (b) and (c), we see that $\sum_{n=1}^{\infty} c_{n}<\infty$. We can easily conclude the desired conclusion with the aid of Lemma 1.2. This completes the proof of Lemma 2.1. 
Theorem 2.2. Let $X$ be a real Banach space and $K$ a nonempty closed and convex subset of $X$. Let $T: K \rightarrow K$ be a asymptotically I-nonexpansive in the intermediate sense and $I: K \rightarrow K a$ asymptotically nonexpansive in the intermediate sense. Assume that $F:=F(T) \cap F(I) \neq \emptyset$. Let $\sigma_{n}=$ $\max \left\{0, \sup _{x, y \in k}\left(\left\|T^{n} x-T^{n} y\right\|-\left\|I^{n} x-I^{n} y\right\|\right)\right\}$ and $\bar{\sigma}_{n}=\max \left\{0, \sup _{x, y \in k}\left(\left\|T^{n} x-T^{n} y\right\|-\|x-y\|\right)\right\}$. Let $\left\{\alpha_{n}\right\},\left\{\beta_{n}\right\},\left\{\gamma_{n}\right\},\left\{\widehat{\alpha}_{n}\right\},\left\{\widehat{\beta}_{n}\right\},\left\{\widehat{\gamma}_{n}\right\}$ be six real number sequences in $(0,1)$. Let $\left\{x_{n}\right\}$ be a sequence generated in the following iterative process:

$$
\begin{gathered}
x_{1} \in C, \\
y_{n}=\widehat{\alpha}_{n} x_{n}+\widehat{\beta}_{n} I^{n} x_{n}+\widehat{\gamma}_{n} v_{n}, \\
x_{n+1}=\alpha_{n} x_{n}+\beta_{n} T^{n} y_{n}+\gamma_{n} u_{n}, \quad n \geq 1,
\end{gathered}
$$

where $\left\{u_{n}\right\}$ and $\left\{v_{n}\right\}$ be two bounded sequences in $K$. Assume that the following restrictions are satisfied:

(a) $\alpha_{n}+\beta_{n}+\gamma_{n}=\widehat{\alpha}_{n}+\widehat{\beta}_{n}+\widehat{\gamma}_{n}=1$;

(b) $\sum_{n=1}^{\infty} \sigma_{n}<\infty, \sum_{n=1}^{\infty} \bar{\sigma}_{n}<\infty$;

(c) $\sum_{n=1}^{\infty} \gamma_{n}<\infty, \sum_{n=1}^{\infty} \widehat{\gamma}_{n}<\infty$.

If both $T$ and I are continuous, then the sequence $\left\{x_{n}\right\}$ strongly converges to a common fixed point of $T$ and $I$ if and only if

$$
\liminf _{n \rightarrow \infty} d\left(x_{n}, F\right)=0
$$

Proof. The necessity is obvious. Next, we prove the sufficiency part of the theorem. Note that continuity of $T$ and $I$ implies that the set $F(T)$ and $F(I)$ are closed. It follows from (2.6) that

$$
\left\|x_{n+1}-p\right\| \leq\left\|x_{n}-p\right\|+c_{n}
$$

This implies in turn that

$$
d\left(x_{n+1}, F\right) \leq d\left(x_{n}, F\right)+c_{n}
$$

Now applying Lemma 1.2 to (2.10), we obtain the existence of the $\operatorname{limit}_{n \rightarrow \infty} d\left(x_{n}, F\right)$. By condition (2.8), we have

$$
\lim _{n \rightarrow \infty} d\left(x_{n}, F\right)=\liminf _{n \rightarrow \infty} d\left(x_{n}, F\right)=0 .
$$


Next we prove that the sequence $\left\{x_{n}\right\}$ is a Cauchy sequence in $K$. For any positive integers $n, m$, from (2.9) it follows that

$$
\begin{aligned}
\left\|x_{n+m}-p\right\| & \leq\left\|x_{n+m-1}-p\right\|+c_{n+m-1} \\
& \leq\left(\left\|x_{n+m-2}-p\right\|+c_{n+m-2}\right)+c_{n+m-1} \\
& \leq \cdots \\
& \leq\left\|x_{n}-p\right\|+\sum_{i=n}^{n+m-1} c_{i} \\
& \leq\left\|x_{n}-p\right\|+\sum_{i=n}^{\infty} c_{i} .
\end{aligned}
$$

Since $\lim _{n \rightarrow \infty} d\left(x_{n}, F\right)=0$, and $\sum_{n=1}^{\infty} c_{n}<\infty$, for any given $\epsilon>0$, there exists a positive integer $n_{0}$ such that

$$
d\left(x_{n}, F\right)<\frac{\epsilon}{8}, \quad \sum_{i=n}^{\infty} c_{i}<\frac{\epsilon}{2}, \quad \forall n \geq n_{0} .
$$

Therefore there exists $p_{1} \in F$ such that $d\left(x_{n}, p_{1}\right)<(\epsilon / 4), \forall n \geq n_{0}$. Consequently, for any $n \geq n_{0}$ and for all $m \geq 1$, we have

$$
\begin{aligned}
\left\|x_{n+m}-x_{n}\right\| & \leq\left\|x_{n+m}-p_{1}\right\|+\left\|x_{n}-p_{1}\right\| \\
& \leq 2\left\|x_{n}-p_{1}\right\|+\sum_{i=n}^{\infty} c_{i} \\
& \leq \frac{\epsilon}{4} \cdot 2+\frac{\epsilon}{2}=\epsilon .
\end{aligned}
$$

This implies that $\left\{x_{n}\right\}$ is a Cauchy sequence in $K$. Let $x_{n} \rightarrow x^{*} \in K$. Since $F$ is closed, this implies that $x^{*} \in F$. This shows that $\left\{x_{n}\right\}$ strongly converges to a common fixed of $T$ and $I$. This completes the proof of Theorem 2.2.

Lemma 2.3. Let $X$ be a real Banach space and $K$ a nonempty closed and convex subset of $X$. Let $T: K \rightarrow K$ be a asymptotically I-nonexpansive in the intermediate sense and $I: K \rightarrow K a$ asymptotically nonexpansive in the intermediate sense. Assume that $F:=F(T) \cap F(I) \neq \emptyset$. Let $\sigma_{n}=$ $\max \left\{0, \sup _{x, y \in k}\left(\left\|T^{n} x-T^{n} y\right\|-\left\|I^{n} x-I^{n} y\right\|\right)\right\}$ and $\bar{\sigma}_{n}=\max \left\{0, \sup _{x, y \in k}\left(\left\|T^{n} x-T^{n} y\right\|-\|x-y\|\right)\right\}$. Let $\left\{\alpha_{n}\right\},\left\{\beta_{n}\right\},\left\{\gamma_{n}\right\},\left\{\widehat{\alpha}_{n}\right\},\left\{\widehat{\beta}_{n}\right\},\left\{\widehat{\gamma}_{n}\right\}$ be six real number sequences in $(0,1)$. Let $\left\{x_{n}\right\}$ be a sequence generated in the following iterative process:

$$
\begin{gathered}
x_{1} \in C, \\
y_{n}=\widehat{\alpha}_{n} x_{n}+\widehat{\beta}_{n} I^{n} x_{n}+\widehat{\gamma}_{n} v_{n}, \\
x_{n+1}=\alpha_{n} x_{n}+\beta_{n} T^{n} y_{n}+\gamma_{n} u_{n}, \quad n \geq 1,
\end{gathered}
$$


where $\left\{u_{n}\right\}$ and $\left\{v_{n}\right\}$ be two bounded sequences in $K$. Assume that the following restrictions are satisfied:

(a) $\alpha_{n}+\beta_{n}+\gamma_{n}=\widehat{\alpha}_{n}+\widehat{\beta}_{n}+\widehat{\gamma}_{n}=1, \forall n \geq 1$;

(b) $\sum_{n=1}^{\infty} \sigma_{n}<\infty, \sum_{n=1}^{\infty} \bar{\sigma}_{n}<\infty$;

(c) there exist constants $\tau_{1}, \tau_{2} \in(0,1)$ such that $\tau_{1} \leq \beta_{n}, \widehat{\beta}_{n} \leq \tau_{2}, \forall n \geq 1$;

(d) $\sum_{n=1}^{\infty} \gamma_{n}<\infty, \sum_{n=1}^{\infty} \widehat{\gamma}_{n}<\infty$.

Then

$$
\begin{aligned}
& \lim _{n \rightarrow \infty}\left\|x_{n}-T^{n} x_{n}\right\|=0, \\
& \lim _{n \rightarrow \infty}\left\|x_{n}-I^{n} x_{n}\right\|=0 .
\end{aligned}
$$

Proof. According to Lemma 2.1, for any $p \in F$, we have $\lim _{n \rightarrow \infty}\left\|x_{n}-p\right\|$ exists. Without loss of generality, we may assume that

$$
\lim _{n \rightarrow \infty}\left\|x_{n}-p\right\|=d,
$$

where $d>0$ is some constant. It follows that

$$
\lim _{n \rightarrow \infty}\left\|x_{n+1}-p\right\|=\lim _{n \rightarrow \infty}\left\|\left(1-\beta_{n}\right)\left[x_{n}-p+\gamma_{n}\left(u_{n}-x_{n}\right)\right]+\beta_{n}\left[T^{n} y_{n}-p+\gamma_{n}\left(u_{n}-x_{n}\right)\right]\right\|=d
$$

Notice that

$$
\left\|x_{n}-p+\gamma_{n}\left(u_{n}-x_{n}\right)\right\| \leq\left\|x_{n}-p\right\|+\gamma_{n}\left\|u_{n}-x_{n}\right\|
$$

It follows from the restriction (d) and (2.18) that

$$
\limsup _{n \rightarrow \infty}\left\|x_{n}-p+\gamma_{n}\left(u_{n}-x_{n}\right)\right\| \leq d
$$


Notice that

$$
\begin{aligned}
\limsup _{n \rightarrow \infty}\left\|T^{n} y_{n}-p+\gamma_{n}\left(u_{n}-x_{n}\right)\right\| & \leq \limsup _{n \rightarrow \infty}\left\|T^{n} y_{n}-p\right\|+\limsup _{n \rightarrow \infty} \gamma_{n}\left\|u_{n}-x_{n}\right\| \\
& =\limsup _{n \rightarrow \infty}\left\|T^{n} y_{n}-p\right\| \\
& \leq \limsup _{n \rightarrow \infty}\left(\left\|I^{n} y_{n}-I^{n} p\right\|+\sigma_{n}\right) \\
& \leq \limsup _{n \rightarrow \infty}\left(\left\|y_{n}-p\right\|+\bar{\sigma}_{n}+\sigma_{n}\right) \\
& =\limsup _{n \rightarrow \infty}\left\|y_{n}-p\right\| \\
& \leq \limsup _{n \rightarrow \infty}\left(\left\|x_{n}-p\right\|+\widehat{\gamma}_{n}\left\|v_{n}-p\right\|+\widehat{\beta}_{n} \bar{\sigma}_{n}\right) \\
& =d .
\end{aligned}
$$

In view of (2.19), (2.21) and (2.22), we obtain from Lemma 1.1 that

$$
\lim _{n \rightarrow \infty}\left\|x_{n}-T^{n} y_{n}\right\|=0
$$

Notice that

$$
\begin{aligned}
\left\|x_{n+1}-x_{n}\right\| & =\left\|\beta_{n}\left(T^{n} y_{n}-x_{n}\right)+\gamma_{n}\left(u_{n}-x_{n}\right)\right\| \\
& \leq \beta_{n}\left\|T^{n} y_{n}-x_{n}\right\|+\gamma_{n}\left\|u_{n}-x_{n}\right\| .
\end{aligned}
$$

It follows from (2.23) and the restriction (d) that

$$
\lim _{n \rightarrow \infty}\left\|x_{n+1}-x_{n}\right\|=0
$$

Notice that

$$
\left\|I^{n} x_{n}-p\right\| \leq\left\|x_{n}-p\right\|+\bar{\sigma}_{n}
$$

It follows that

$$
\limsup _{n \rightarrow \infty}\left\|I^{n} x_{n}-p\right\| \leq d
$$

On the other hand, we have

$$
\lim _{n \rightarrow \infty}\left\|y_{n}-p\right\|=\lim _{n \rightarrow \infty}\left\|\left(1-\widehat{\beta}_{n}\right)\left[x_{n}-p+\widehat{\gamma}_{n}\left(v_{n}-x_{n}\right)\right]+\widehat{\beta}_{n}\left[I^{n} x_{n}-p+\widehat{\gamma}_{n}\left(v_{n}-x_{n}\right)\right]\right\|=d .
$$


Notice that

$$
\left\|x_{n}-p+\widehat{\gamma}_{n}\left(v_{n}-x_{n}\right)\right\| \leq\left\|x_{n}-p\right\|+\widehat{\gamma}_{n}\left\|v_{n}-x_{n}\right\| .
$$

It follows that

$$
\limsup _{n \rightarrow \infty}\left\|x_{n}-p+\widehat{\gamma}_{n}\left(v_{n}-x_{n}\right)\right\| \leq d
$$

Notice that

$$
\left\|I^{n} x_{n}-p+\widehat{\gamma}_{n}\left(v_{n}-x_{n}\right)\right\| \leq\left\|I^{n} x_{n}-p\right\|+\widehat{\gamma}_{n}\left\|v_{n}-x_{n}\right\| .
$$

It follows from (2.27) that

$$
\limsup _{n \rightarrow \infty}\left\|I^{n} x_{n}-p+\widehat{\gamma}_{n}\left(v_{n}-x_{n}\right)\right\| \leq d
$$

In view of (2.28), (2.30), and (2.32), we obtain from Lemma 1.1 that

$$
\lim _{n \rightarrow \infty}\left\|x_{n}-I^{n} x_{n}\right\|=0
$$

On the other hand, we have

$$
\begin{aligned}
\left\|x_{n}-T^{n} x_{n}\right\| & \leq\left\|x_{n}-T^{n} y_{n}\right\|+\left\|T^{n} y_{n}-T^{n} x_{n}\right\| \\
& \leq\left\|x_{n}-T^{n} y_{n}\right\|+\left\|y_{n}-x_{n}\right\|+\sigma_{n}+\bar{\sigma}_{n} \\
& \leq\left\|x_{n}-T^{n} y_{n}\right\|+\widehat{\beta}_{n}\left\|I^{n} x_{n}-x_{n}\right\|+\widehat{\gamma}_{n}\left\|v_{n}-x_{n}\right\|+\sigma_{n}+\bar{\sigma}_{n} .
\end{aligned}
$$

In view of (2.23) and (2.33), we have $\lim _{n \rightarrow \infty}\left\|x_{n}-T^{n} x_{n}\right\|=0$. This completes the proof of Lemma 2.3.

Theorem 2.4. Let $X$ be a real Banach space and $K$ a nonempty closed and convex subset of $X$. Let $T: K \rightarrow K$ be a asymptotically I-nonexpansive in the intermediate sense and $I: K \rightarrow K a$ asymptotically nonexpansive in the intermediate sense. Assume that $F:=F(T) \cap F(I) \neq \emptyset$. Let $\sigma_{n}=$ $\max \left\{0, \sup _{x, y \in k}\left(\left\|T^{n} x-T^{n} y\right\|-\left\|I^{n} x-I^{n} y\right\|\right)\right\}$ and $\bar{\sigma}_{n}=\max \left\{0, \sup _{x, y \in k}\left(\left\|T^{n} x-T^{n} y\right\|-\|x-y\|\right)\right\}$. Let $\left\{\alpha_{n}\right\},\left\{\beta_{n}\right\},\left\{\gamma_{n}\right\},\left\{\widehat{\alpha}_{n}\right\},\left\{\widehat{\beta}_{n}\right\},\left\{\widehat{\gamma}_{n}\right\}$ be six real number sequences in $(0,1)$. Assume that both $T$ and I are Lipschitz continuous. Let $\left\{x_{n}\right\}$ are a sequence generated in the following iterative process:

$$
\begin{gathered}
x_{1} \in C, \\
y_{n}=\widehat{\alpha}_{n} x_{n}+\widehat{\beta}_{n} I^{n} x_{n}+\widehat{\gamma}_{n} v_{n}, \\
x_{n+1}=\alpha_{n} x_{n}+\beta_{n} T^{n} y_{n}+\gamma_{n} u_{n}, \quad n \geq 1,
\end{gathered}
$$


where $\left\{u_{n}\right\}$ and $\left\{v_{n}\right\}$ be two bounded sequences in $K$. Assume that the following restrictions are satisfied:

(a) $\alpha_{n}+\beta_{n}+\gamma_{n}=\widehat{\alpha}_{n}+\widehat{\beta}_{n}+\widehat{\gamma}_{n}=1, \forall n \geq 1$;

(b) $\sum_{n=1}^{\infty} \sigma_{n}<\infty, \sum_{n=1}^{\infty} \bar{\sigma}_{n}<\infty$;

(c) there exist constants $\tau_{1}, \tau_{2} \in(0,1)$ such that $\tau_{1} \leq \beta_{n}, \widehat{\beta}_{n} \leq \tau_{2}, \forall n \geq 1$;

(d) $\sum_{n=1}^{\infty} \gamma_{n}<\infty, \sum_{n=1}^{\infty} \widehat{\gamma}_{n}<\infty$.

If at least one of the mappings $T$ and $I$ is compact, then the sequence convergence strongly to a common fixed point of $T$ and $I$.

Proof. Without loss of generality, we may assume that $T$ is compact; this means that there exists a subsequence $\left\{T^{n_{k}} x_{n_{k}}\right\}$ of $\left\{T^{n} x_{n}\right\}$ such that $\left\{T^{n_{k}} x_{n_{k}}\right\}$ converges strongly to $x^{*} \in K$, then (2.16) implies that $\left\{x_{n_{k}}\right\}$ converges strongly to $x^{*}$. Since $T$ is continuous, then $\left\{T^{n_{k}+1} x_{n_{k}}\right\}$ converges strongly to $T x^{*}$. On the other hand, according to (2.17) and the continuity of $I$, we obtain that $\left\{I^{n_{k}} x_{n_{k}}\right\},\left\{I^{n_{k}+1} x_{n_{k}}\right\}$ converge strongly to $x^{*}, I x^{*}$, respectively. Since $\lim _{k \rightarrow \infty}\left\|x_{n_{k}+1}-x_{n_{k}}\right\|=0$, then

$$
\begin{aligned}
\left\|I^{n_{k}+1} x_{n_{k}+1}-I^{n_{k}+1} x_{n_{k}}\right\| & \leq\left\|x_{n_{k}+1}-x_{n_{k}}\right\|+\bar{\sigma}_{n_{k}} \longrightarrow 0, \text { as } k \longrightarrow \infty, \\
\left\|T^{n_{k}+1} x_{n_{k}+1}-T^{n_{k}+1} x_{n_{k}}\right\| & \leq\left\|I^{n_{k}+1} x_{n_{k}+1}-I^{n_{k}+1} x_{n_{k}}\right\|+\sigma_{n_{k}} \\
& \leq\left\|x_{n_{k}+1}-x_{n_{k}}\right\|+\bar{\sigma}_{n_{k}}+\sigma_{n_{k}} \longrightarrow 0, \text { as } k \longrightarrow \infty .
\end{aligned}
$$

Observe that

$$
\begin{aligned}
\left\|x^{*}-T x^{*}\right\| \leq & \left\|x^{*}-x_{n_{k}+1}\right\|+\left\|x_{n_{k}+1}-T^{n_{k}+1} x_{n_{k}+1}\right\| \\
& +\left\|T^{n_{k}+1} x_{n_{k}+1}-T^{n_{k}+1} x_{n_{k}}\right\|+\left\|T^{n_{k}+1} x_{n_{k}}-T x^{*}\right\|, \\
\left\|x^{*}-I x^{*}\right\| \leq & \left\|x^{*}-x_{n_{k}+1}\right\|+\left\|x_{n_{k}+1}-I^{n_{k}+1} x_{n_{k}+1}\right\| \\
& +\left\|I^{n_{k}+1} x_{n_{k}+1}-I^{n_{k}+1} x_{n_{k}}\right\|+\left\|I^{n_{k}+1} x_{n_{k}}-I x^{*}\right\| .
\end{aligned}
$$

Taking limit as $k \rightarrow \infty$ in the above inequality, we find $x^{*}=T x^{*}, x^{*}=I x^{*}$, which means $x^{*} \in F$. However, due to Lemma 2.1, the $\operatorname{limit} \lim _{n \rightarrow \infty}\left\|x_{n}-x^{*}\right\|$ exists, therefore

$$
\lim _{n \rightarrow \infty}\left\|x_{n}-x^{*}\right\|=\lim _{k \rightarrow \infty}\left\|x_{n_{k}}-x^{*}\right\|=0,
$$

which means that $\left\{x_{n}\right\}$ converges strongly to $x^{*} \in F$. This completes the proof of Theorem 2.4.

\section{Acknowledgment}

The work was supported by Natural Science Foundation of Zhejiang Province (Y6110270). 


\section{References}

[1] K. Goebel and W. A. Kirk, "A fixed point theorem for asymptotically nonexpansive mapping," Proceedings of the American Mathematical Society, vol. 35, pp. 171-174, 1972.

[2] B. Bruck, T. Kuczumow, and S. Reich, "Convergence of iterates of asymptotically nonexpansive mappings in Banach space with the uniform Opial property," Colloquium Mathematicum, vol. 65, pp. 169-179, 1993.

[3] W. A. Kirk, "Fixed point theorems for non-Lipschitzian mappings of asymptotically nonexpansive type," Israel Journal of Mathematics, vol. 17, no. 4, pp. 339-346, 1974.

[4] X. Qin, S. S. Chang, and Y. J. Cho, "Iterative methods for generalized equilibrium problems and fixed point problems with applications," Nonlinear Analysis: Real World Applications, vol. 11, no. 4, pp. 29632972, 2010.

[5] S. Y. Cho and S. M. Kang, "Approximation of fixed points of pseudocontraction semigroups based on a viscosity iterative process," Applied Mathematics Letters, vol. 24, no. 2, pp. 224-228, 2011.

[6] S. Y. Cho and S. M. Kang, "Approximation of common solutions of variational inequalities via strict pseudocontractions," Acta Mathematica Scientia, vol. 32, no. 4, pp. 1607-1618, 2012.

[7] J. K. Kim, Y. M. Nam, and J. Y. Sim, "Convergence theorems of implicit iterative sequences for a finite family of asymptotically quasi-nonexpansive type mappings," Nonlinear Analysis: Theory, Methods and Applications, vol. 71, no. 12, pp. e2839-e2848, 2009.

[8] S. M. Kang, S. Y. Cho, and Z. Liu, "Convergence of iterative sequences for generalized equilibrium problems involving inverse-strongly monotone mappings," Journal of Inequalities and Applications, vol. 2010, Article ID 827082, 16 pages, 2010.

[9] J. K. Kim, S. Y. Cho, and X. Qin, "Hybrid projection algorithms for generalized equilibrium problems and strictly pseudocontractive mappings," Journal of Inequalities and Applications, vol. 2010, Article ID 312602, 18 pages, 2010.

[10] S. Y. Cho, S. M. Kang, and X. Qin, "Hybrid projection algorithms for treating common fixed points of a family of demicontinuous pseudocontractions," Applied Mathematics Letters, vol. 25, no. 5, pp. 854-857, 2012.

[11] Y. Su and S. Li, "Composite implicit iteration process for common fixed points of a finite family of strictly pseudocontractive maps," Journal of Mathematical Analysis and Applications, vol. 320, no. 2, pp. 882-891, 2006.

[12] X. Qin, S. Y. Cho, and S. M. Kang, "Iterative algorithms for variational inequality and equilibrium problems with applications," Journal of Global Optimization, vol. 48, no. 3, pp. 423-445, 2010.

[13] S. Yang and W. Li, "Iterative solutions of a system of equilibrium problems in Hilbert spaces," Advances in Fixed Point Theory, vol. 1, no. 1, pp. 15-26, 2011.

[14] X. Qin, S. Y. Cho, and S. M. Kang, "Strong convergence of shrinking projection methods for quasi- $\phi-$ nonexpansive mappings and equilibrium problems," Journal of Computational and Applied Mathematics, vol. 234, no. 3, pp. 750-760, 2010.

[15] J. Ye and J. Huang, "Strong convergence theorems for fixed point problems and generalized equilibrium problems of three relatively quasi-nonexpansive mappings in Banach spaces," Journal of Mathematical and Computational Science, vol. 1, no. 1, pp. 1-18, 2011.

[16] S. Husain and S. Gupta, "A resolvent operator technique for solving generalized system of nonlinear relaxed cocoercive mixed variational inequalities," Advances in Fixed Point Theory, vol. 2, no. 1, pp. 18-28, 2012.

[17] X. Qin, Y. J. Cho, and S. M. Kang, "Convergence theorems of common elements for equilibrium problems and fixed point problems in Banach spaces," Journal of Computational and Applied Mathematics, vol. 225, no. 1, pp. 20-30, 2009.

[18] X. Qin, S. Y. Cho, and S. M. Kang, "On hybrid projection methods for asymptotically quasi- $\phi-$ nonexpansive mappings," Applied Mathematics and Computation, vol. 215, no. 11, pp. 3874-3883, 2010.

[19] F. Gu, "Some convergence theorems of non-implicit iteration process with errors for a finite families of I-asymptotically nonexpansive mappings," Applied Mathematics and Computation, vol. 216, no. 1, pp. 161-172, 2010.

[20] S. Lv and C. Wu, "Convergence of iterative algorithms for a generalized variational inequality and a nonexpansive mapping," Engineering Mathematics Letters, vol. 1, no. 1, pp. 44-57, 2012.

[21] J. Schu, "Weak and strong convergence to fixed points of asymptotically nonexpansive mappings," Bulletin of the Australian Mathematical Society, vol. 43, no. 1, pp. 153-159, 1991. 
[22] F. Mukhamedov and M. Saburov, "Strong convergence of an explicit iteration process for a totally asymptotically I-nonexpansive mapping in Banach spaces," Applied Mathematics Letters, vol. 23, no. 12, pp. 1473-1478, 2010.

[23] S. Temir, "On the convergence theorems of implicit iteration process for a finite family of $I$ asymptotically nonexpansive mappings," Journal of Computational and Applied Mathematics, vol. 225, no. 2, pp. 398-405, 2009.

[24] F. Mukhamedov and M. Saburov, "Weak and strong convergence of an implicit iteration process for an asymptotically quasi-I-nonexpansive mapping in Banach space," Fixed Point Theory and Applications, vol. 2010, Article ID 719631, 13 pages, 2010.

[25] N. Shahzad, "Generalized I-nonexpansive maps and best approximations in Banach spaces," Demonstratio Mathematica, vol. 37, pp. 597-600, 2004.

[26] K. K. Tan and H. K. Xu, "Approximating fixed points of nonexpansive mappings by the Ishikawa iteration process," Journal of Mathematical Analysis and Applications, vol. 178, no. 2, pp. 301-308, 1993. 


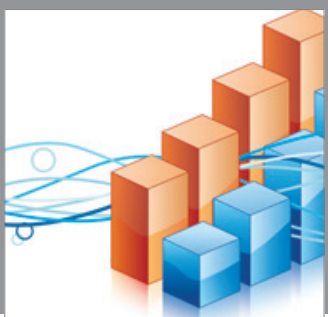

Advances in

Operations Research

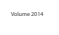

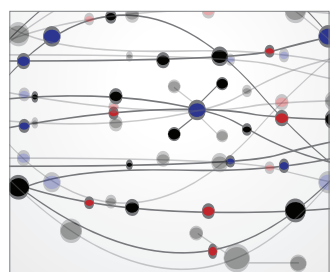

\section{The Scientific} World Journal
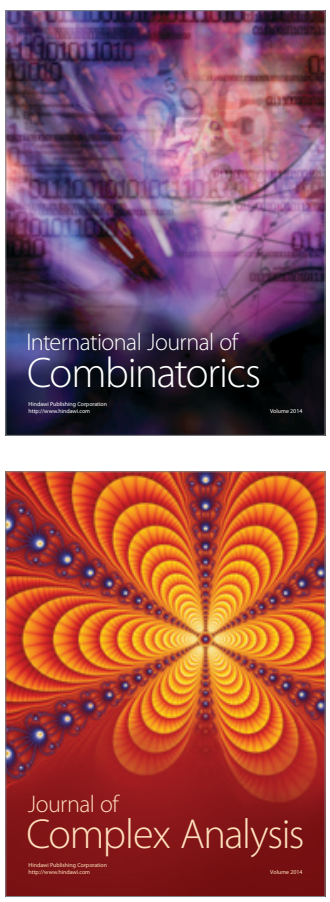

International Journal of

Mathematics and

Mathematical

Sciences
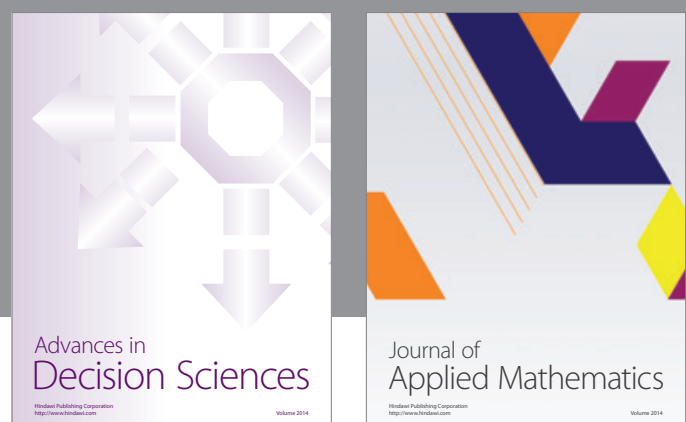

Journal of

Applied Mathematics
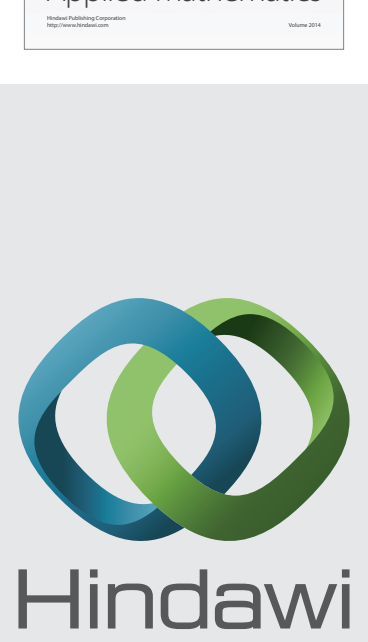

Submit your manuscripts at http://www.hindawi.com
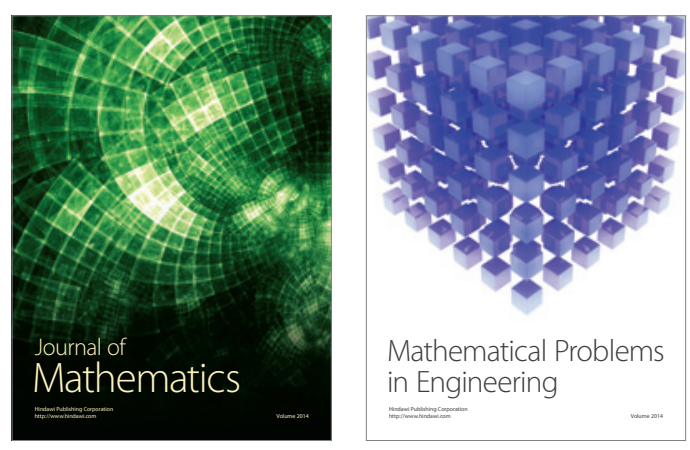

Mathematical Problems in Engineering
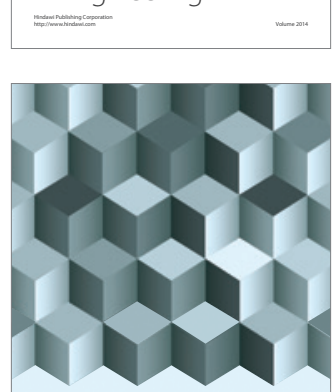

Journal of

Function Spaces
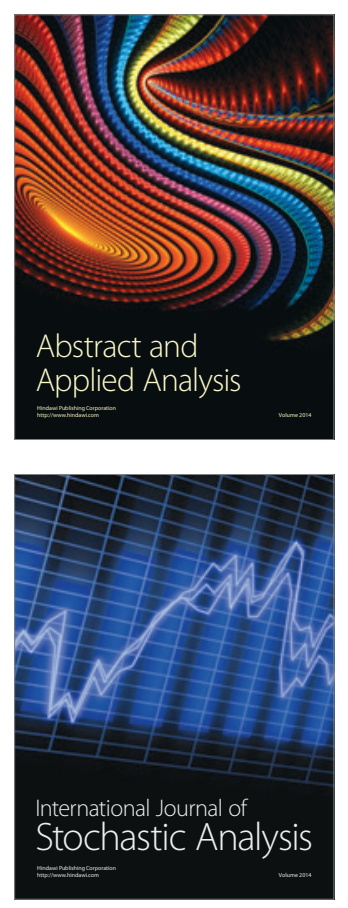

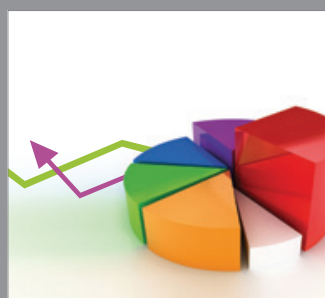

ournal of

Probability and Statistics

Promensencen
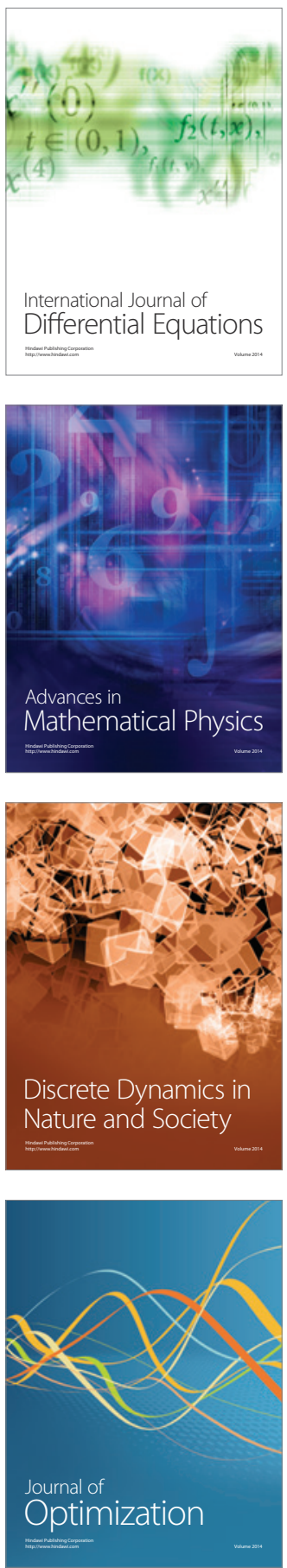